Institute of $\mathbf{F}_{\text {ood and }} \mathbf{A}_{\text {gricultural }} \mathbf{S}_{\text {ciences }}$

\title{
Manual de los Reglamentos del Agua de Florida: Notas and Glosario 1
}

Michael T. Olexa, Laura Minton, Dulcy Miller, y Sarah Corbett ${ }^{2}$

\section{Agradecimientos}

Los autores agradecen a Richard Budell de la Oficina de Política del Agua Agrícola del Departamento de Agricultura y Servicios al Consumidor de Florida. Los autores también agradecen a David H. Hammonds, Consultor del Programa de Salud Ambiental, Oficina de Programas de Aguas de Drenaje en el Sitio, del Departamento de Salud de Florida, y a Edward A. Bettinger, Consultor del Programa de Salud Ambiental, Oficina de Programas de Agua del Departamento de Salud de Florida.

\author{
Notas \\ El Centro de Servicio de Información del \\ Medio Ambiente puede contactar a cualquier persona \\ a la Región 4 o ayudar a preguntas relacionadas con \\ la agencia, de Lunes a Viernes de las 8:00 am a las \\ 5:00 pm, al (404) 562- 9900 o bien al (800) \\ 241-1754.
}

\section{Glosario}

IMPUESTO AD VALOREM - impuesto sobre el valor de la propiedad.

PERTENENCIA POR DERECHO- cualquier mejora artificial a una presa que puede afectar la capacidad de mantener tal dique o de la reservorio o al lago creado para tal presa.

1. Este es el documento EDIS FE091, una publicación del Department of Food and Resource Economics, Florida Cooperative Extension Service, Institute of Food and Agricultural Sciences, University of Florida, Gainesville, FL. Publicada Novembre 2002. Por favor visite la página electrónica EDIS en http://edis.ifas.ufl.edu.

2. Michael T. Olexa, es profesor del Department of Food and Resource Economics, Florida Cooperative Extension Service, Institute of Food and Agricultural Sciences, University of Florida, Gainesville, FL; y miembro de Florida Bar; Presidente de Agricultural Law Committee of The Florida Bar; y Director del Agricultural Law Center. Laura Minton, Dulcy Miller, y Sarah Corbett son estudiantes graduadas de Levin College of Law, University of Florida, Gainesville, FL. Filiberto Reyes-Villanueva fue el traductor de la versión en ingles al español.

Esta publicación esta diseñada para proporcionar información precisa, actualizada y autorizada sobre esta material. Sin embargo, ya que las leyes, reglas administrativas y decisiones de la corte, sobre las cuales están basados, están sujetas a revisión constante; algunas partes de esta publicación podrían ser obsoletas en cualquier momento. Esta publicación es distribuida bajo el entendimiento que los autores no están involucrados en ninguna representación legal u otros servicios profesionales, y que la información contenida aquí no debe ser considerada como un substituto de una asesoria legal. Esta publicación no esta completa en proporcionar toda la información para lograr el cumplimiento de las leyes y reglamentos que gobiernan la protección del agua. Por estas razones, el uso de estos manuales por cualquier persona constituye un acuerdo para mantener libre de daño a los autores, al Florida Cooperative Extension Service, al Institute of Food and Agricultural Sciences, y a la University of Florida por cualquier demanda por responsabilidad de daños, o gastos en que pueda incurrir cualquier persona, como un resultado de hacer referencia o confianza sobre la información contenida en esta publicación. Esta publicación fue apoyada financieramente por el Florida Department of Agriculture and Consumer Services.

EI Instituto de Alimentos y Ciencias Agrícolas es Un empleador que opera bajo Acción Afirmativa y provee Oportunidades Igualitarias, dedicado a promocionar la investigación, a información educativa y otros servicios, únicamente a los individuos e instituciones que operan baj discriminación sin considerar color, raza, sexo, edad, incapacidad u origen. Para más información sobre como obtener otras publicaciones de la extensión, comuníquese con la oficina de Servicio de Extensión de su condado. Servicio de Extensión de la Florida / Instituto de Alimentos y Ciencias Agrícolas / Universidad de la Florida / Christine Taylor Waddill, Decana. 
ACUÍFERO - enorme subterráneo proveedor de agua, el cual en Florida está almacenado en cuevas de piedra caliza porosa.

COMITES DE CUENCAS - comité para manejo de agua con autoridad para desarrollar planes para el uso de agua.

PRACTICAS DE MEJOR MANEJO (PMM) manejo y prácticas culturales diseñadas para conservar y usar eficientemente la tierra.

AGUAS NEGRAS - aguas de desecho provenientes de inodoros o cocinas de sitios residenciales.

CARCINÓGENO - un agente que ha sido probado científicamente que causa cáncer.

SISTEMA CERRADO - es un sistema que ni intercambia materia ni energía con su alrededor.

FELONIA / DELITO - las felonías son usualmente castigadas con altas multas y / o sentencias de prisión, mientras que los delitos son ofensas mas bajas que las felonías y se castigan con multas menores y / o sentencias en prisión mas cortas.

AGUAS GRISES - son aguas de desecho de residencias (baños, lavadoras, etc.).

DESECHOS PELIGROSOS - desecho considerado por la APA como una amenaza para la salud humana o al medio ambiente; no incluye el petróleo, aunque algunos productos de petróleo son desechos peligrosos.

POZOS DE INYECCIÓN - fuente de agua u otros líquidos entrando en aguas subterráneas; puede ser un pozo muy profundo u otros tipos de corrientes de lluvia.

ALIVIO INYUCTIVO - orden de la corte para prohibir a alguien a hacer algún acto especifico o mandar a alguien a anular algún error o daño ( ej. restringiendo una orden).

\section{RESPONSABILIDAD CONJUNTA Y}

SEPARADA - cuando una parte que fue agraviada puede demandar a una o mas de las partes ofensoras, ya sea separadamente o juntas ( responsabilidad junta e individual).

DEMANDA - una demanda o cargo sobre la propiedad por pago o alguna deuda, obligación o deber.

RESPONSABILIDAD - el estado de ser limitado u obligado por la ley para ejecutar, pagar o hacer el bien sobre alguna cosa.

FILTRADO - es el proceso por el cual los nutrientes químicos o contaminantes son disueltos y arrastrados por el agua o son movidos hacia las capas mas bajas del suelo.

MITIGACION - hacer menos severo, reducir una penalidad o castigo impuesto por la ley.

NIVELES MINIMOS DE AGUA - niveles de agua debajo del cual, los retiros pueden ser dañinos al ecosistema o a los recursos del agua; establecidos por los distritos de manejo de agua.

NEGLIGENCIA - es la falla para usar el cuidado que una persona razonablemente prudente y cuidadosa debería usar en circunstancias similares.

NEGLIGENCIA PER SE - es una forma de negligencia que resulta de la violación de un estatuto ( ej. pasarse una luz roja de semáforo).

FUENTE DE NO PUNTO - es una fuente no conocida de contaminación (ej. corrientes de agua agrícola y corrientes de agua urbana).

BPC - Bifenil Poly Clorado, un producto carcinógeno común.

PLAGUICIDAS - es cualquier sustancia usada para regular, prevenir, repeler o destruir cualquier plaga o planta.

FUENTE DE PUNTO - es una vía acuática conocida a través del cual se descargan los desechos ( ej. tubería, alcantarillas y canales).

CONTAMINANTE - presencia de contaminante en el agua, suelo o aire a tal grado que el uso del recurso es perjudicado, incluyendo gasolina o aceite, cualquier plaguicida o cualquier compuesto derivado de amonio o cloro. 
RECLAMACION - proceso de incremento de minado de tierra $\mathrm{u}$ otro recurso usado para incrementar el valor debido al cambio físico de la tierra (e.j., reclamos de pantanos).

DESECHO SÓLIDO - basura, sedimento, semi liquido, y desecho gaseoso; no incluye aguas servidas domesticas, irrigación de flujo de retorno o contaminantes incluidos en los permisibles por NPDES.

RESPONSABILIDAD ESTRICTA - es la responsabilidad sin falla, cuando uno es responsable por todas las consecuencias consideradas en la falla de uno.

ESPECIES AMENAZADAS/ O EN PELIGRO DE EXTINCIÓN - especies de plantas o animales que están amenazadas con la extinción o están en peligro de extinción.

SUSTANCIAS TOXICAS - sustancias que conllevan un riesgo de producir defectos de nacimiento, enfermedades del corazón, enfisema u otros problemas de salud en humanos o que inducen un riesgo a dañar el medio ambiente.

\section{RESPONSABILIDAD VICARIA -} responsabilidad del empleador, basada sobre las acciones de empleo que ocurra dentro del propósito de su empleado/a.

PANTANOS - tierras que mantienen vegetación apropiada al medio ambiente de pantanos y / o cubierta, periódicamente con agua.

ZONA DE DESCARGA - predefinida como un área de maleza tridimensional alrededor de la fuente de agua que llega al suelo, usualmente tiene menores estándares de calidad de agua, antes de que el agua alcance a suplir el agua subterránea. 